\title{
Crystalline structure and reinforcement in hybrid PP composites
}

\author{
R. Várdai ${ }^{1,2} \circledast$ Á. Schäffer ${ }^{1,2} \cdot$ M. Ferdinánd ${ }^{1,2} \cdot$ T. Lummerstorfer $^{3} \cdot$ M. Jerabek ${ }^{3} \cdot$ M. Gahleitner ${ }^{3} \cdot$ G. Faludi ${ }^{1,2}$. \\ J. Móczó ${ }^{1,2} \cdot$ B. Pukánszky ${ }^{1,2}$
}

Received: 27 July 2021 / Accepted: 24 August 2021 / Published online: 18 September 2021

(c) The Author(s) 2021

\begin{abstract}
Hybrid composites were prepared from a PP homopolymer, talc and PVA fibers by twin-screw extrusion and injection molding. Talc was added to improve stiffness, while the fibers serve to increase impact resistance. Mechanical properties were characterized by tensile and impact testing, while structure was studied by SEM and optical microscopy. The results showed that talc has a strong nucleating effect in the PP used in spite of the fact that the grade contained a nucleating agent inherently. PVA also nucleated the PP slightly, with trans-crystallization occurring around the fibers. The effect of the two components was independent of each other on lamella thickness, but crystallinity decreased with increasing PVA content in the hybrid composites. The results clearly showed that crystalline structure changes considerably upon the addition of the two components, both lamella thickness and crystallinity increasing. However, somewhat contradictorily, the effect of these changes on the mechanical properties of the composites is small. Model calculations have shown that stiffness increases by about $0.5 \mathrm{GPa}$ due to nucleation, while moduli as large as $7 \mathrm{GPa}$ are reached by the addition of talc. Impact resistance is completely independent of lamella thickness or crystallinity; this property is determined mainly by local deformation processes initiated by the PVA fibers. Dispersed structure and the direct effect of the additive determine properties in the hybrid composites studied, and the role of crystalline structure is of secondary importance.
\end{abstract}

Keywords PVA fibers $\cdot$ Impact resistance $\cdot$ Lamella thickness $\cdot$ Crystallinity $\cdot$ Modeling $\cdot$ Structure-property correlations

\section{Introduction}

Polypropylene (PP) is a commodity polymer offering exceptional price/performance ratio in a very wide range of applications $[1,2]$. It is extensively used by the automotive industry $[3,4]$, but also by a large number of other fields $[2,5,6]$. The polymer has the reasonable stiffness of about $1.5 \mathrm{GPa}$, but the impact resistance of homopolymers is small, in the range of $2 \mathrm{~kJ} \mathrm{~m}^{-2}$ for typical molding grades with melt flow rates of $20-100 \mathrm{~g}(10 \mathrm{~min})^{-1}$ at $230{ }^{\circ} \mathrm{C}$ and $2.16 \mathrm{~kg}$ load.

\section{R. Várdai}

vardai.robert@vbk.bme.hu

1 Laboratory of Plastics and Rubber Technology, Department of Physical Chemistry and Materials Science, Budapest University of Technology and Economics, P.O. Box 91, 1521 Budapest, Hungary

2 Institute of Materials and Environmental Chemistry, Research Centre for Natural Sciences, P.O. Box 286, 1519 Budapest, Hungary

3 Borealis Polyolefine GmbH, St.-Peter-Strasse 25, 4021 Linz, Austria
Many applications require larger stiffness and considerably better impact strength; the combination of 2-3 GPa stiffness and $15 \mathrm{~kJ} \mathrm{~m}^{-2}$ impact resistance is a common requirement especially in the automotive industry. In order to achieve this and other property combinations, PP is often modified by various means. Elastomers $[7,8]$, mostly ethylene propylene rubber (EPR) $[9,10]$ and ethylene propylene diene monomer (EPDM) copolymers [8, 11], are often added to increase impact strength, but such a modification usually leads to the decrease of stiffness [8]. This latter property can be improved by the addition of fillers or fibers [12,13], but impact resistance suffers in this case. In order to circumvent the problem, the industry came up with the solution of producing hybrid materials containing at least two different additives: one improving stiffness, while the other impact resistance [14-20].

The first hybrid PP composites contained an elastomer and a filler or fiber in order to achieve the goal mentioned above $[14,16,21,22]$. The material has been and is still being used for the production of bumpers for cars and other technical components in the automotive and appliance 
sector. The principle worked quite well for a long time, but as the use of natural reinforcements gained more and more importance with time, new difficulties emerged. The solution of using an elastomer for impact modification was not successful with wood flour and other natural reinforcements [23]. Although the stiffness of PP increased quite considerably almost invariably, impact strength remained very small even at large elastomer content exceeding 30 mass\% [24]. Cavitation and the fracture of the natural reinforcement resulted in the limited impact resistance [24], meaning that a different solution had to be found. The approach that proved to be very successful was the introduction of organic fibers, mainly poly(ethylene terephthalate) (PET) [25] or poly(vinyl alcohol) (PVA), into a PP matrix reinforced with traditional fibers (glass, carbon) [25]. Very large stiffness (6-8 GPa) and impact resistance $\left(15-20 \mathrm{~kJ} / \mathrm{m}^{2}\right)$ could be achieved by the approach even in the case of natural reinforcements [25].

Most reinforcing fibers are relatively expensive compared to particulate fillers, and the concept of using these latter for the reinforcement of hybrid PP composite impact modified with organic fibers has not been tried before. The filler used in the largest quantity in PP is talc, which has several advantages in this particular polymer. Talc has anisotropic particle geometry and thus reinforces injection molded parts because of its orientation [26] and it nucleates PP quite strongly, thus modifying its crystalline structure and properties [27]. The introduction of talc into PP increases the temperature of crystallization through heterogeneous nucleation, which results in the change of all aspects of crystalline structure except crystal modification. Spherulite size, lamella thickness, the number of tie molecules and crystallinity are all modified by the presence of the filler [28]. Close correlation has been shown earlier between crystalline structure and the mechanical properties of PP. Young's modulus was shown to depend mainly on lamella thickness and crystallinity [29], while impact resistance is influenced more by lamella thickness [30]. Accordingly, the preparation of hybrid PP composites containing talc as reinforcement and an organic fiber for impact modification results in a new material in which the modifiers have an effect on properties directly as heterogeneities and indirectly through changing the crystalline structure of the matrix. One of the crucial questions of practice, and also of this paper, is the relative magnitude of the two effects and the influence of changing crystalline structure on properties.

In line with the considerations discussed above, the goal of this work was to check the concept of the impact modification of PP with organic fibers in a polymer reinforced not with traditional fibers, but with an inorganic filler, talc in this case. Taking into consideration the strong nucleating effect of talc in PP, we studied the effect of the components on the structure of the matrix polymer. Using previous experience, we tried to establish correlations between structure and properties, and determine the relative role of crystalline and the heterogeneous, dispersed structure on composite properties. Further aspects of crystallization and nucleation as well as relevance for practice are discussed briefly in the last section of the paper.

\section{Experimental}

\section{Materials}

The polypropylene used as matrix in the experiments was the Daplen HJ 325 MO grade homopolymer (PP) of Borealis $\mathrm{GmbH}$ (Austria) with a melt flow rate (MFR) value of $50 \mathrm{~g}$ $(10 \mathrm{~min})^{-1}\left(2.16 \mathrm{~kg}, 230{ }^{\circ} \mathrm{C}\right)$ and a density of $0.91 \mathrm{~g} \mathrm{~cm}^{-3}$. Poly(vinyl alcohol) (PVA) fibers were added to improve the impact resistance of the composites. The PVA fiber used was the Kuralon VPB-103 grade obtained from Kuraray, Japan. The original length of the fibers was $3 \mathrm{~mm}$ and their diameter $11 \mu \mathrm{m}$. The stiffness and strength of the fibers were $10 \mathrm{GPa}$ and $780 \mathrm{MPa}$ according to the producer. The talc used was the Jetfine 3CA grade obtained from Imerys Performance Minerals (France). The particle characteristics of the filler were determined by sedimentation and a laser light scattering (Mastersizer 3000, Malvern, England). The median diameter of the particles are 1.0 and $3.9 \mu \mathrm{m}$, while their D95 values are 3.5 and $7.8 \mu \mathrm{m}$, respectively, according to the two methods. Particle size analysis indicates that the particles are relatively small. This grade of talc is specifically recommended by the producer to achieve enhanced nucleation in crystalline polymers. The hybrid composites always contained 20 mass $\%$ of talc, and the amount of the PVA fibers changed from 0 to 40 mass\% in 5 mass\% steps.

\section{Sample preparation}

The components were homogenized using a twin-screw compounder (Brabender DSK 42/7, Brabender, Germany) at the set temperatures of $170-180-190-195{ }^{\circ} \mathrm{C}$ and $40 \mathrm{~min}^{-1}$. The compounder is designed for distributive mixing achieved by cuts in the screw flights and the relatively large screw diameter of $42 \mathrm{~mm}$ and small L/D ratio of 7 . Before extrusion, the PVA fibers were dried at $80{ }^{\circ} \mathrm{C}$ for $4 \mathrm{~h}$ in a vacuum oven. Extrusion was repeated once in order to increase homogeneity. The granulated composites were dried at $80{ }^{\circ} \mathrm{C}$ for $4 \mathrm{~h}$, and then, they were injection molded into standard (ISO 527 1A) tensile bars of $4 \mathrm{~mm}$ thickness using a Demag IntElect 50/330-100 machine (Demag, Germany). Processing parameters were 40-175-185-190$200{ }^{\circ} \mathrm{C}$ set temperatures, $300-1200$ bar injection pressure, depending on the type and content of the additive, $50 \mathrm{bar}$ back pressure, $50 \mathrm{~mm} \mathrm{~s}^{-1}$ injection speed, $25 \mathrm{~s}$ holding time and $30 \mathrm{~s}$ cooling time. The temperature of the mold was set 
to $40{ }^{\circ} \mathrm{C}$. The specimens were stored at ambient temperature $\left(23{ }^{\circ} \mathrm{C}, 50 \% \mathrm{RH}\right)$ for a week before further testing.

\section{Characterization, measurements}

The mechanical properties of the composites were characterized by tensile and impact testing. Tensile tests were carried out according to the ISO 527 standard using an Instron 5566 universal testing machine (Instron, USA) with a gauge length of $115 \mathrm{~mm}$ and $5 \mathrm{~mm} \mathrm{~min}^{-1}$ crosshead speed. Modulus, yield properties (yield stress and yield strain), tensile strength and elongation at break were derived from recorded stress vs. strain traces. Impact resistance was characterized by the notched Charpy impact strength, which was determined according to the ISO $1791 \mathrm{eA}$ standard at $23{ }^{\circ} \mathrm{C}$ and $2 \mathrm{~mm}$ notch depth. The dispersed structure of the composites was studied on broken surfaces by scanning electron microscopy (Jeol JSM 6380 LA, Jeol Ltd., Japan). The broken surface of the samples was sputtered with gold before recording the micrographs. Melting and crystallization characteristics as well as some aspects of the crystalline structure were studied by differential scanning calorimetry (DSC). The measurements were carried out using a PerkinElmer DSC apparatus. Two heating and a cooling run were done on 3-5 mg samples, which were taken from the middle of the injection molded specimens. The samples were heated up to $220^{\circ} \mathrm{C}$ with $10{ }^{\circ} \mathrm{C} \mathrm{min}^{-1}$ heating rate, kept there $3 \mathrm{~min}$ and then cooled down to $30^{\circ} \mathrm{C}$ with the same rate. Heat of transformation and crystallinity were always calculated for the amount of the matrix polymer in the composites. Crystallization and crystalline structure were characterized also by polarization optical microscopy (POM). POM studies were performed in polarized light using a Zeiss Axioscop 20 microscope (Zeiss, Germany) equipped with a Mettler FP82 hot stage (Mettler Toledo, USA). The sample was crystallized under isothermal condition $\left(\mathrm{T}=124{ }^{\circ} \mathrm{C}\right)$ after the elimination of thermal and mechanical history by holding the samples at $\mathrm{T}=220^{\circ} \mathrm{C}$ for $5 \mathrm{~min}$.

\section{Results and discussion}

The results are presented in several sections. The possible nucleation effect of the components is discussed first, followed by the dispersed morphology of the composite and the crystalline structure of the polymer. Mechanical properties as well as the effect of crystalline structure on them are presented in the next section, while correlations and relevance for practice are discussed in the last section of the paper.

\section{Nucleating effect of the components}

Talc has a strong nucleating effect in PP, which modifies crystalline structure considerably. This effect, however, must be considered together with the fact that the PP used in this study is a nucleated grade. One might wonder about the sense of studying the nucleation effect of a filler or reinforcement in a nucleated grade, but several factors are relevant here. First of all, the goal of the project was to improve stiffness and impact resistance by the combination of talc and the PVA fiber. Additionally, nucleating agents are used in small quantities in a way to optimize effect and cost. Further components, the filler and the organic fiber, can have additional nucleating effect without doubt, and nucleation may change crystalline structure and composite properties as a result. We wanted to obtain information about the extent of the changes originating in the additional nucleating effect of the two components.

The easiest and most practical way of detecting nucleation in PP is the study of the crystallization of the polymer by DSC. The crystallization traces of the polymer containing various amounts of talc are presented in Fig. 1. The traces unambiguously prove that talc has a strong nucleating effect even at 5 mass\% talc content in spite of the presence of the nucleating agent added in polymer production. Crystallization temperature increases considerably, and also the area under the crystallization peak seems to increase upon the addition of the filler. Increasing the amount of talc increases the temperature of crystallization

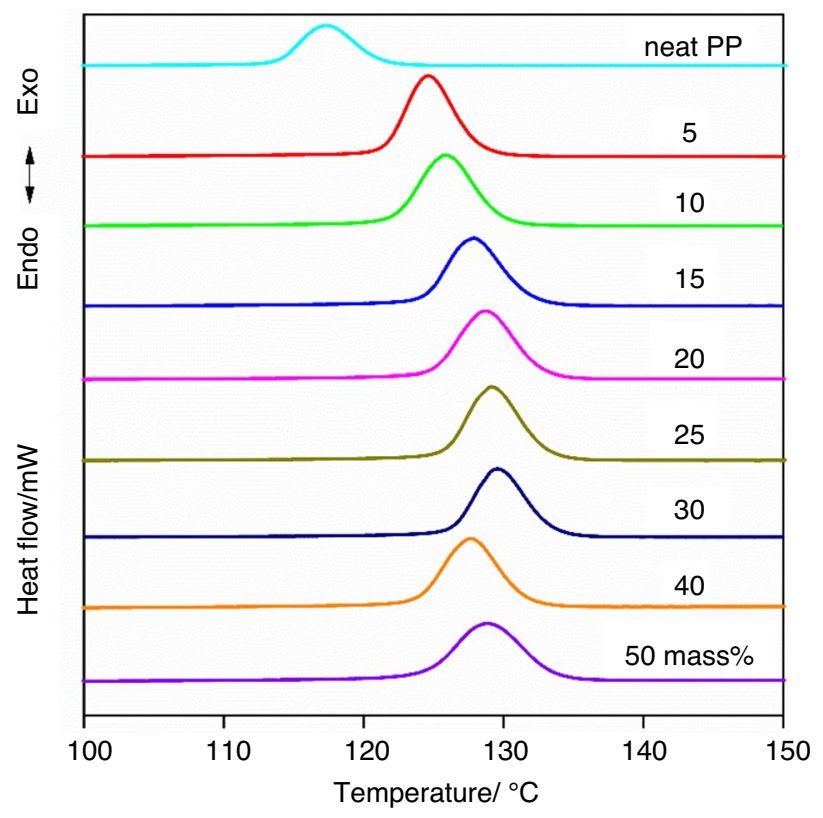

Fig. 1 Nucleating effect of talc in the PP used as matrix polymer. Cooling traces recorded at $10{ }^{\circ} \mathrm{C} \mathrm{min}{ }^{-1}$ cooling rate. The numbers on the individual traces indicate the amount of talc in the composite 


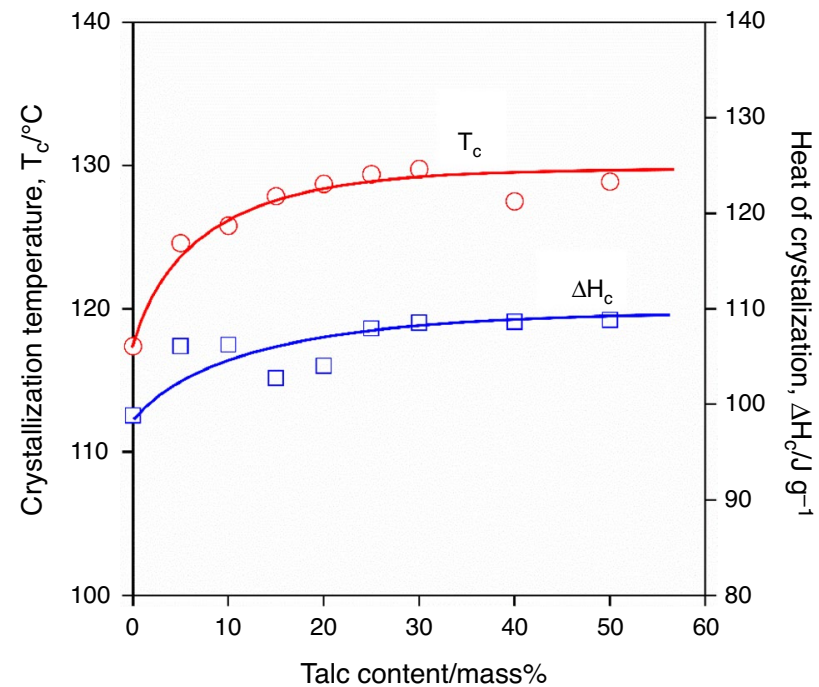

Fig. 2 Dependence of the temperature $\left(\mathrm{T}_{\mathrm{c}}\right)$ and heat $\left(\Delta \mathrm{H}_{\mathrm{c}}\right)$ of crystallization of PP on the amount of talc in two-component PP composites. Symbols: (red circle) $\mathrm{T}_{c}$, (blue square) $\Delta \mathrm{H}_{\mathrm{c}}$

further, but this increase is not proportional to the amount of the filler added, but apparently approaches a saturation value.

The extent of nucleation and the effect of talc content on the temperature of crystallization is easier to follow in Fig. 2 showing the composition dependence of the temperature and heat of crystallization. The inherent nucleation of the grade is proved by the high crystallization temperature of about $117^{\circ} \mathrm{C}$. However, the strong nucleating effect of talc is clearly shown by the further, approximately $10{ }^{\circ} \mathrm{C}$ increase of $\mathrm{T}_{\mathrm{c}}$. Crystallinity also increases somewhat as a consequence of nucleation. $T_{c}$ is related to lamella thickness, higher crystallization temperatures resulting in thicker lamellae [31], while the heat of crystallization is proportional to crystallinity, both influencing the mechanical properties of the polymer considerably.

The nucleating effect of talc is well known not only in PP, but also in other crystalline polymers. On the other hand, practically no information is available about the possible nucleating effect of PVA fibers. These fibers are rarely used in polymers, but mostly to reinforce concrete [32-35], and they have been shown to increase the impact resistance of PP only recently [36]. The temperature and heat of crystallization of the polymer is plotted against the amount of PVA fibers added in Fig. 3. Both characteristics increase slightly upon the addition of the smallest amount of fibers, but do not change much afterward. Accordingly, we may conclude that PVA fibers also have a slight nucleating effect in our PP, but it is not as strong as that of talc. Accordingly, both components added to reinforce and impact modify PP nucleate

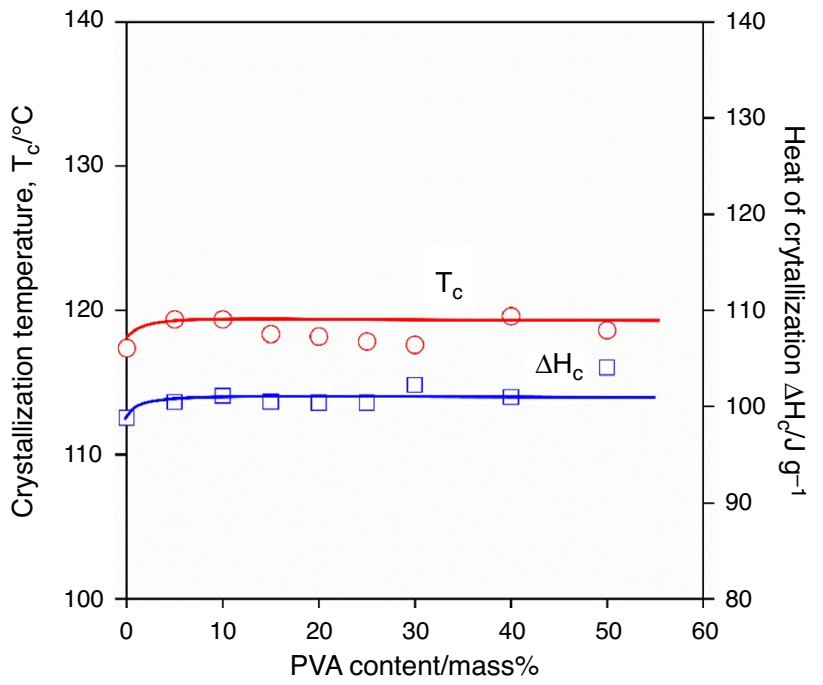

Fig. 3 Effect of the amount of PVA fibers on the crystallization characteristics of the PP used in the experiments. Symbols: (red circle) $\mathrm{T}_{\mathrm{c}}$, (blue square) $\Delta \mathrm{H}_{\mathrm{c}}$

the polymer to some extent and they may even interact and influence the effect of the other.

\section{Structure of hybrid composites}

The composites prepared have dispersed structure and the polymer is crystalline. Accordingly, both structures must be studied and the distribution of the components as well as the characteristics of the crystalline structure must be determined. A SEM micrograph recorded on the fracture surface of a composite containing 20 mass $\%$ talc and 20 mass\% PVA fiber is presented in Fig. 4a. At this magnification, the micrograph is dominated by the fibers which debonded from the matrix during failure. Because of their smaller size, the talc particles are hardly visible on the surface. Figure $4 \mathrm{~b}$ shows the surface of a composite containing only 5 mass\% fiber in order to be able to observe also the distribution of the talc particles. The amount of these latter is 20 mass\% also in this case. We can see that both talc and PVA are evenly distributed in the composite and they do not interact with each other. We may assume that the individual components act independently and their nucleating effect is additive, although it may also occur that one might dominate over the other.

The crystallization temperature of the polymer in the hybrid composites is plotted against additive content in Fig. 5. In the case of the hybrid materials, the polymer containing 20 mass\% talc is regarded as matrix and additive content indicates the amount of PVA fiber in the composite. The same approach applies also to the subsequent figures, i.e., Figures 6 and 8. The values are compared to those obtained on the two-component materials earlier. The strong 

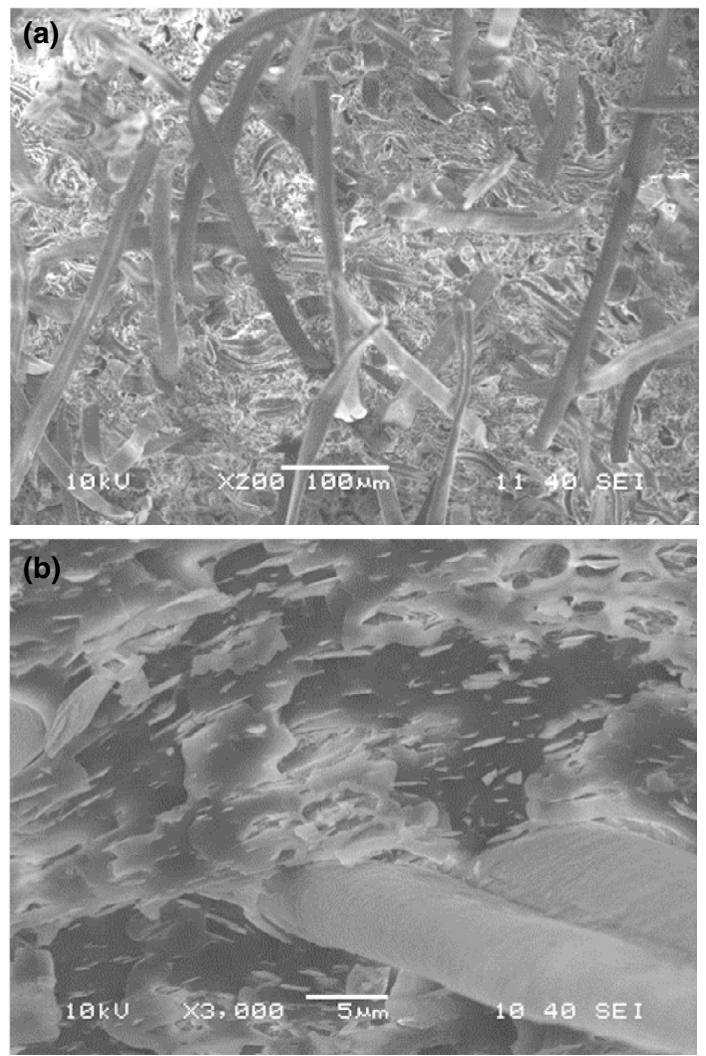

Fig. 4 Dispersed structure of PP/talc/PVA hybrid composites. a 20 mass\% talc and 20 mass\% PVA, magnification: 200x, b 20 mass $\%$ talc and 5 mass\% PVA, magnification: 3000x

nucleating effect of talc and the smaller one of PVA is evident in the figure. The hybrid composite contains 20 mass $\%$ talc that is shown by the high crystallization temperature at zero PVA fiber content. The addition of the fibers does not change the temperature of crystallization practically at all. One might speculate about the slight increase with increasing PVA content or the drop in $\mathrm{T}_{\mathrm{c}}$ at 5 mass\% PVA fiber content in the hybrid composite, but differences are small and well within the standard deviation of the measurement. Further experiments are needed to verify the existence of the phenomena and to decrease the standard deviation of the data. Obviously, the strong nucleating effect of talc determines also the crystalline structure of the hybrid composites.

Besides the temperature of crystallization, i.e., lamella thickness, usually crystallinity also changes upon nucleation. The effect of composition on the heat of crystallization is presented in Fig. 6. The stronger effect of talc and the slight influence of PVA are visible also in this case. The change of crystallinity in the hybrid composite is interesting and difficult to explain. The relatively large value of the composite containing 20 mass\% talc and no PVA fiber clearly originates in the strong nucleating effect of the filler. The slight increase at small PVA content, if it exists at all,

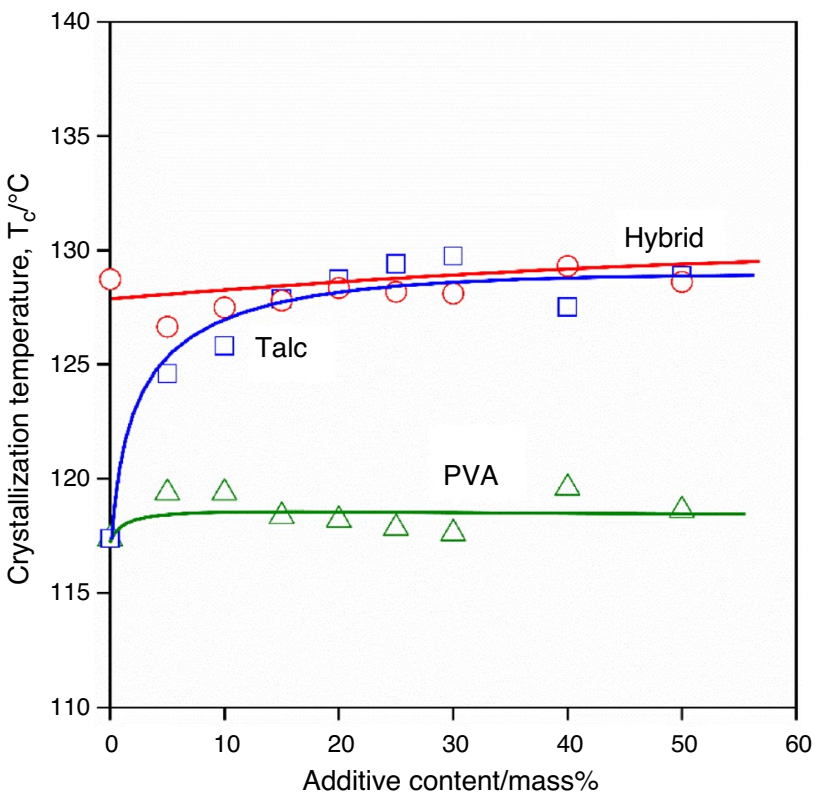

Fig. 5 Influence of composition on the crystallization temperature of two- and three-component PP composites. Symbols: (blue square) talc, (green triangle) PVA, (red circle) hybrid. In the case of the hybrid materials, the polymer containing 20 mass $\%$ talc is regarded as the matrix and additive content indicates the amount of PVA fiber in the composites

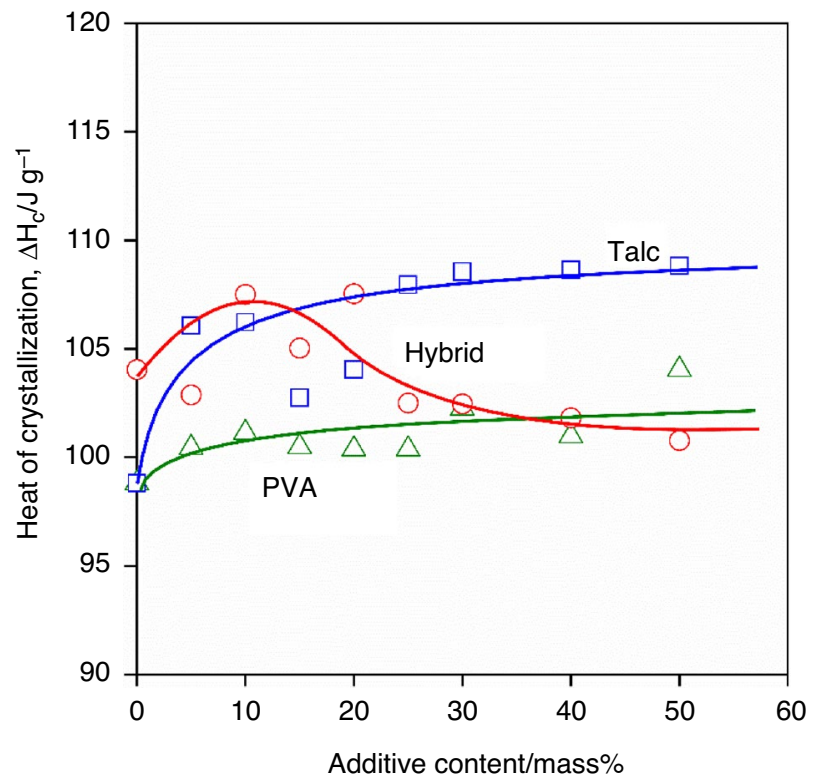

Fig. 6 Dependence of the heat of crystallization of two-component and hybrid PP composites on the amount of additive. Symbols: (blue square) talc, (green triangle) PVA, (red circle) hybrid

but especially the considerable decrease at larger amount of PVA fibers are unexpected, at least based on the study of the two-component materials. Since the two components 


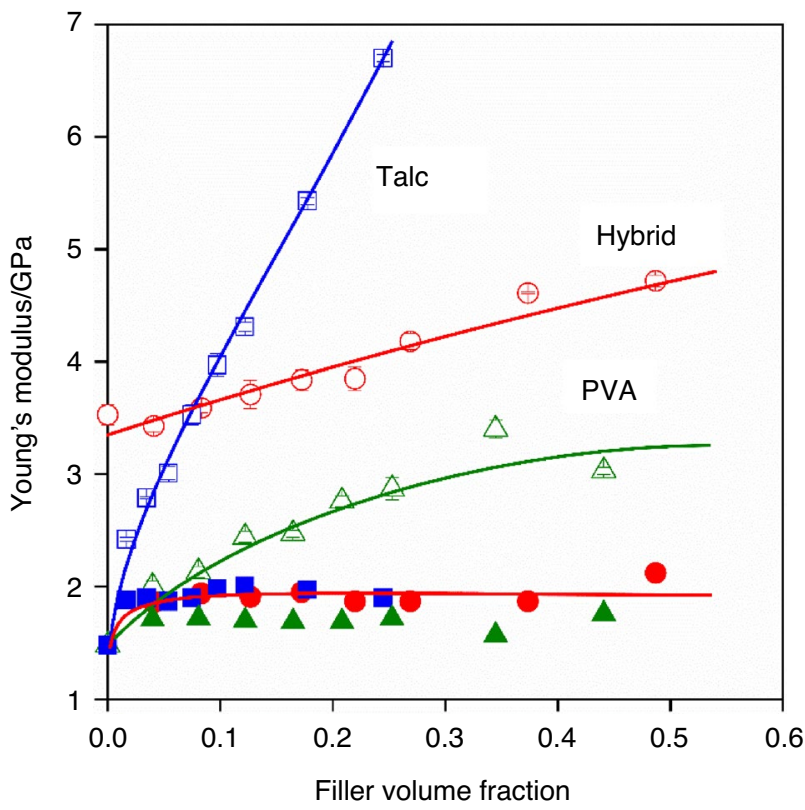

Fig. 7 Effect of composition on the Young's modulus of PP composites. Comparison to prediction. Symbols: (blue square, blue filled square) talc, (green triangle, green filled triangle) PVA, (red circle, red filled circle) hybrid. Empty symbols: measured values; full symbols: calculated from the temperature and heat of crystallization using Eq. 1

do not interact with each other, the negative effect of PVA is difficult to understand. It is also hard to believe that PP interacts more with PVA than with talc, since the surface energy of the former is much smaller $\left(37 \mathrm{~mJ} \mathrm{~m}^{-2}\right)$ [37] than that of the latter $\left(210 \mathrm{~mJ} \mathrm{~m}^{-2}\right)$ [38]. We must accept that the addition of the PVA fibers to the composite containing 20 mass\% talc hinders the crystallization of PP in some way, but the phenomenon needs further study and considerations.

\section{Tensile and impact properties}

The results presented in the previous section proved that the crystalline structure of the PP matrix changes upon the addition of the two components: talc and PVA. The question is to which extent these changes influence composite properties. The stiffness of the composites is plotted against additive content in Fig. 7. Talc is added to the polymer to improve stiffness, and the Young's modulus of PP increases considerably indeed. The effect of PVA is smaller although it reinforces PP as well. The extent of reinforcement depends on the modulus of the components as well as on their volume fraction in the composite. The modulus of talc is around 30 $\mathrm{GPa}$ [39], while that of PVA is $10 \mathrm{GPa}$ in the direction of the length of the fiber, according to the producer. In the case of anisotropic fillers, platelets, e.g., talc, and fibers, e.g., PVA, orientation is an additional factor, but the flexible organic fibers were shown to twist and entangle [36]; thus, this factor does not play an important role in reinforcement. Because of the presence of talc, the modulus of the hybrid composite is relatively large at zero PVA content and increases upon the addition of the fibers approximately to the same extent as in the case of the two-component PP/PVA composite. According to the results, the reinforcing effect of the two components is more or less additive.

The effect of the changes in crystalline structure on properties can be estimated with the help of models. A very simple, empirical model was developed earlier to describe the effect of lamella thickness and crystallinity on the Young's modulus of various neat and nucleated PP grades [29]. The model takes into consideration lamella thickness by the temperature of crystallization $\left(\mathrm{T}_{\mathrm{c}}\right)$, while crystallinity by the heat of crystallization $\left(\Delta \mathrm{H}_{\mathrm{c}}\right)$ in the following way:

$E=0.014 T_{\mathrm{c}}+0.018 \Delta H_{\mathrm{c}}-1.77$.

The equation does not cover the entire possible range of the variables, but describes experimental results very successfully in the range encountered in practice [40-43]. Models exist which describe the entire range of crystallinity and lamella thickness possible, but they are much more complicated and difficult to use $[44,45]$. The results of DSC measurements are available for all two-component and hybrid composites; thus, Young's modulus can be calculated from Eq. 1. Calculated moduli are also plotted in Fig. 7 as full symbols. Modulus increases somewhat at the smallest additive content due to the strong nucleating effect of talc, but does not change much afterward. The effect of any changes in crystalline structure on properties is much weaker, almost by an order of magnitude, than that of the direct effect of the dispersed additives, either talc or PVA. The influence of dispersed particles on properties is obviously much stronger than that of the surrounding crystalline structure of the polymer.

PVA fibers were added to the polymer to improve its impact resistance. The impact strength of the composites is plotted against additive content in Fig. 8. Talc does not influence impact resistance practically at all, but the PVA fibers increase it considerably as expected. The impact strength of the hybrid composites is somewhat smaller; talc particles increase stiffness and hinder the plastic deformation of the matrix. The effect of the additives on impact resistance completely corresponds to expectations, but we do not know anything about the effect of crystalline structure on this property.

The impact strength of various neat and nucleated PP grades was shown to depend more on lamella thickness than on crystallinity [46]. The dispersed, two-phase structure of a heterophasic PP copolymer resulted in larger impact resistance, but lamella thickness also had some influence. 


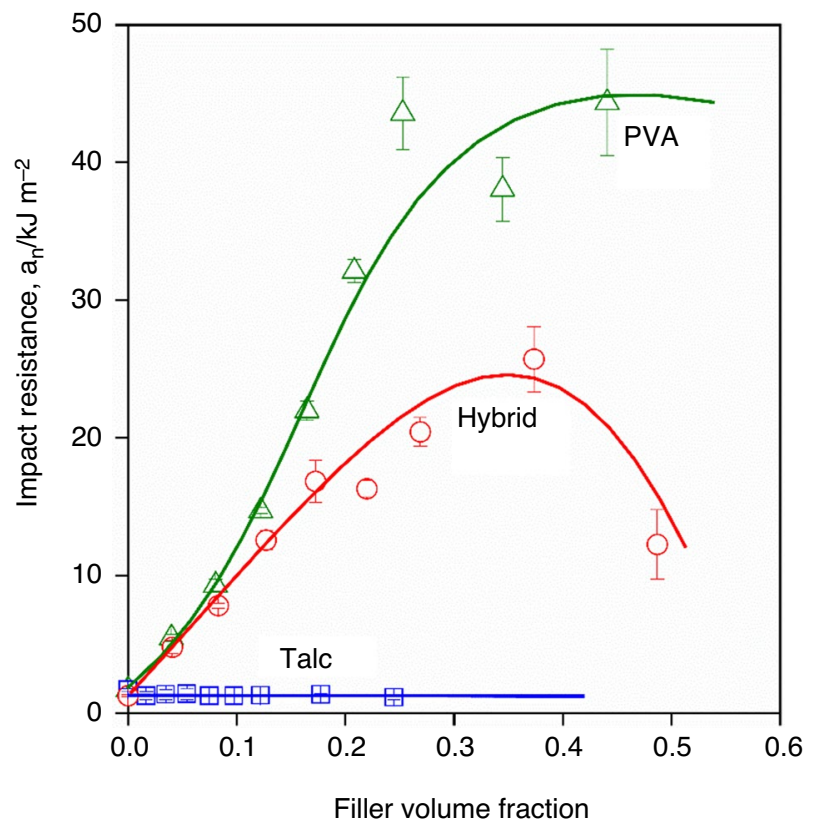

Fig. 8 Effect of the additives on the impact resistance of two-component and hybrid composites. Symbols: (blue square) talc, (green triangle) PVA, (red circle) hybrid

Unfortunately, we are not aware of any quantitative model describing the relationship of impact strength and the crystalline structure of PP, but we plotted impact resistance against the temperature of crystallization, related to lamella thickness, in Fig. 9. According to the results shown in the figure, impact strength is completely independent of the changes in crystalline structure and it is determined exclusively by local deformation processes initiated by the dispersed additives. These processes depend on the type of the additives and composition, but not on changes in the crystalline structure of the matrix polymer.

\section{Discussion}

The results presented above might contradict the expectations of some claiming that crystalline structure must determine properties. Hutley and Darlington [47] found a more or less linear correlation between the crystallization temperature as well as the rate of crystallization and the falling mass impact strength of particulate filled PP, while Maiti [48] observed an even better, linear correlation between the crystallinity and tensile characteristics of $\mathrm{CaCO}_{3}$ filled PP. One could refer to the fact, for example, that the stiffness of an average PP homopolymer is around $1.5 \mathrm{GPa}$, which can be increased up to $2.7-3.0 \mathrm{GPa}$ by the proper adjustment of molecular architecture and nucleation. The almost $100 \%$ change in stiffness through the modification of crystalline structure indicates the very strong role of the latter.

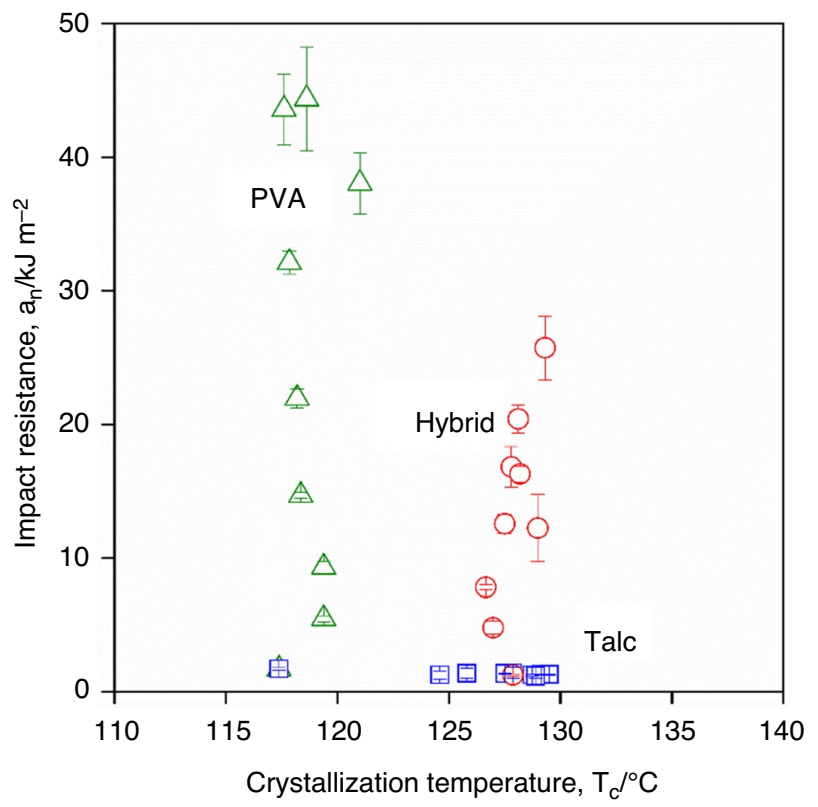

Fig. 9 Lack of correlation between the impact resistance of the composites and the temperature of crystallization (lamella thickness) of the matrix polymer. Symbols: (blue square) talc, (green triangle ) PVA, (red circle) hybrid

However, we must consider also the other side of the equation, the dispersed structure of polymer composites and the influence of local deformation processes.

The modulus of composites is determined mainly by the properties of the components and composition. Although the theoretical stiffness of perfect PP crystals is calculated as $40 \mathrm{GPa}[49,50]$, larger than $3 \mathrm{GPa}$ modulus could not be achieved in PP either by annealing or nucleation [51]. The stiffness of talc or glass fibers is much larger, 30-100 $\mathrm{GPa}$; thus, the large modulus of the composites and the small effect of crystalline structure are not very surprising. Nucleation resulting in thicker lamellae and larger crystallinity decreases impact resistance in most homopolymers [46]. The addition of the PVA fibers increased impact strength to a very large extent, because of the local deformation processes initiated by the fibers. Due to the small surface energy and weak adhesion of the fibers to the polymer, these latter debond under the effect of external load, and this debonding together with the ensuing plastic deformation increases impact strength. In the case of strong adhesion, even the fracture of the fibers consumes more energy than that of the matrix polymer $[36,52,53]$. All evidence indicates that the dispersed, heterophasic morphology of hybrid composites dominates over the changes of crystalline structure caused by the nucleation effect of the additives.

Finally, another factor related to the PVA fibers is worth to consider here. These fibers had a small nucleating effect in the polymer used in these experiments (see Fig. 2). 


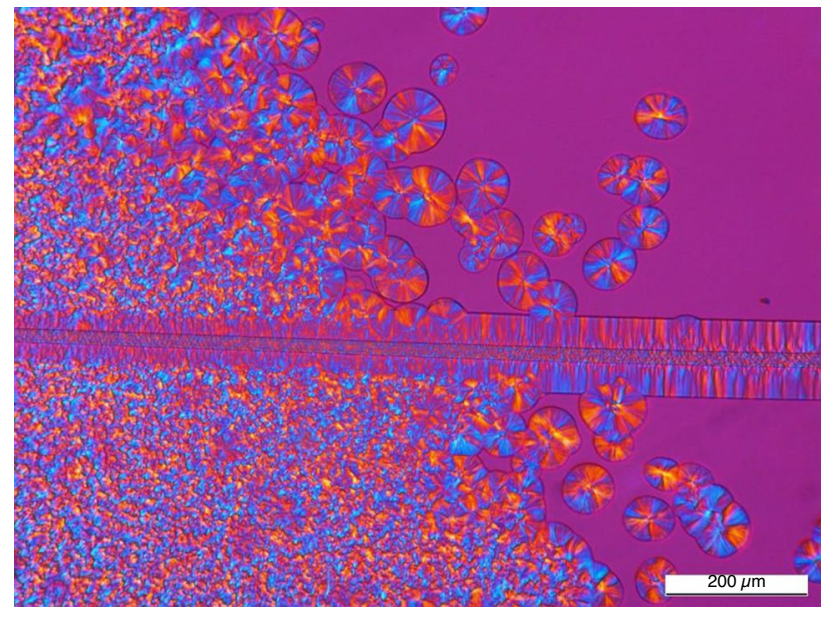

Fig. 10 Trans-crystallization around a PVA fiber in the PP used as matrix in the experiments

Nucleation by the fibers may, however, lead to anisotropic crystalline structure as shown by Fig. 10. Trans-crystallinity develops around the fibers even in the nucleated polymer. The role and effect of trans-crystallinity were strongly debated questions several decades ago [54-56]. Although much experimental and theoretical work was done on transcrystallinity in PP, neither a positive nor a negative effect on the final properties could be proved unambiguously [55, 56]. Trans-crystallization on the surface of PVA fibers might be one of the reasons for the decrease of crystallinity with increasing fiber content (see Fig. 6), although the exact relationship is not clear at present.

\section{Conclusions}

The experiments aimed at the determination of the effect of the crystalline structure of the polymer on the properties of its hybrid composites containing talc and PVA fibers showed that talc has a strong nucleating effect in the PP used. The nucleation effect is considerable in spite of the fact that the grade used contained a nucleating agent inherently. PVA also nucleated the PP slightly, trans-crystallization occurred around the fibers. The effect of the two components was independent of each other on lamella thickness, but crystallinity decreased with increasing PVA content in the hybrid composites. The results clearly showed that crystalline structure changes considerably upon the addition of the two components, and both lamella thickness and crystallinity increased. However, somewhat contradictorily, the effect of these changes on the mechanical properties of the composites is small. Model calculations have shown that stiffness increases by about $0.5 \mathrm{GPa}$ due to nucleation while moduli as large as $7 \mathrm{GPa}$ are reached by the addition of talc. Impact resistance is completely independent of lamella thickness or crystallinity and this property is determined mainly by the local deformation processes initiated by the PVA fibers. Dispersed structure and the direct effect of the additive determines properties in the hybrid composites studied and the role of crystalline structure is of secondary importance.

Acknowledgements The authors acknowledge the financial support of the Comet program of Austria and that of the National Scientific Research Fund of Hungary (OTKA Grant No. FK 129270) for this project on the modification of polymeric materials. This work was also supported by the ÚNKP-20-4-I-BME-327 New National Excellence Program of the Ministry for Innovation and Technology from the source of the National Research, Development and Innovation Fund. One of the authors (RV) is grateful also to the Pro Progressio Foundation for its support.

Author contributions RV was involved in methodology, investigation, data curation, writing the original draft, visualization, writing, reviewing and editing. ÁS and MF carried out investigation and data curation. TL took part in conceptualization, resources, writing, reviewing and editing. MJ did writing, reviewing and editing. MG had contributed to resources, writing, reviewing and editing, supervision and funding acquisition. GF performed formal analysis, investigation and resources. $\mathrm{JM}$ was involved in conceptualization, methodology, data curation and writing the original draft. BP had contributed to conceptualization, methodology, writing the original draft and supervision.

Funding Open access funding provided by the Budapest University of Technology and Economics. Funding for this study was received from the Comet program of Austria, the National Scientific Research Fund of Hungary (OTKA Grant No. FK 129270), the New National Excellence Program of the Ministry for Innovation and Technology from the source of the National Research, Development and Innovation Fund (ÚNKP-20-4-I-BME-327), Pro Progressio Foundation.

Data Availability The raw/processed data required to reproduce these findings cannot be shared at this time due to legal or ethical reasons.

\section{Declarations}

Conflict of interest The authors declare that they have no conflict of interest.

Open Access This article is licensed under a Creative Commons Attribution 4.0 International License, which permits use, sharing, adaptation, distribution and reproduction in any medium or format, as long as you give appropriate credit to the original author(s) and the source, provide a link to the Creative Commons licence, and indicate if changes were made. The images or other third party material in this article are included in the article's Creative Commons licence, unless indicated otherwise in a credit line to the material. If material is not included in the article's Creative Commons licence and your intended use is not permitted by statutory regulation or exceeds the permitted use, you will need to obtain permission directly from the copyright holder. To view a copy of this licence, visit http://creativecommons.org/licenses/by/4.0/. 


\section{References}

1. Moore EP. Polypropylene handbook: polymerization, characterization, properties, processing, applications. Munich Hanser Publishers; 1996.

2. Kissel WJ, Han JH, Meyer JA. Polypropylene: Structure, Properties, Manufacturing Processes and Applications. In: Karian H, editor. Handbook of polypropylene and polypropylene composites, revised and expanded. Boca Raton: CRC Press; 2003.

3. Flowers B. Automotive applications for polypropylene and polypropylene composites. In: Karian H, editor. Handbook of polypropylene and polypropylene composites, revised and expanded. Boca Raton: CRC Press; 2003. p. 578-86.

4. Elliott ANA, editor. Automotive applications of polymers II. Shrewsbury: Rapra Technology Limited; 1992.

5. Güneri A (2005) Polymers in construction. Shrewsbury: Rapra Technology Limited

6. Agarwal S, Gupta RK. Plastics in buildings and construction. In: Kutz M, editor. Applied Plastics Engineering Handbook (Second Edition). William Andrew Publishing; 2017. p. 635-49.

7. Karger-Kocsis J, Kallo A, Kuleznev VN. Phase structure of impact-modified polypropylene blends. Polymer. 1984;25(2):27986. https://doi.org/10.1016/0032-3861(84)90337-9.

8. Martuscelli E (1995) Structure and properties of polypropyleneelastomer blends. In: Karger-Kocsis J, editor. Polypropylene Structure, blends and composites: Volume 2 Copolymers and Blends. Dordrecht: Springer Netherlands. p. 95-140.

9. Mighri F, Huneault MA, Ajji A, Ko GH, Watanabe F. Rheology of EPR/PP blends. J Appl Polym Sci. 2001;82(9):2113-27. https:// doi.org/10.1002/app.2057.

10. Li Y, Xu J-T, Dong Q, Wang X-P, Fu Z-S, Fan Z-Q. Effect of microstructure of EPR on crystallization and morphology of PP/ EPR blends. Polym-Plast Technol Eng. 2008;47(12):1242-9. https://doi.org/10.1080/03602550802497297.

11. Medintseva TI, Erina NA, Prut EV. Specifics of the structure and mechanical properties of blends of isotactic polypropylene with ethylene-propylene-diene elastomer. Polym Sci Ser A. 2008;50(6):647-55. https://doi.org/10.1134/S0965545X080600 84.

12. Katz HS, Milevski JV. Handbook of fillers and reinforcements for plastics. New York: Van Nostrand; 1978.

13. Chu FP. Glass fiber-reinforced polypropylene. In: Karian H, editor. Handbook of polypropylene and polypropylene composites, revised and expanded. Boca Raton: CRC Press; 2003. p. 281-351.

14. Stamhuis JE (1984) Mechanical properties and morphology of polypropylene composites. Talc-filled, elastomer-modified polypropylene. Polym Compos. https://doi.org/10.1002/pc.750050308.

15. Stamhuis JE (1988) Mechanical properties and morphology of polypropylene composites. III. Short glass fiber reinforced elastomer modified polypropylene. Polym Compos 9(4): 280-4. doi:https://doi.org/10.1002/pc.750090406.

16. Kolarík J, Lednický F. Structure of polypropylene/EPDM elastomer/calcium carbonate composites. In: Sedlácek B, editor. Polymer Composites. Berlin: Walter de Gruyter; 1986. p. 537-44.

17. Long Y 1996 Shanks RA. PP/elastomer/filler hybrids II Morphologies and fracture. J Appl Polym Sci. 62(4): 639-46. doi:https:// doi.org/10.1002/(SICI)1097-4628(19961024)62:4<639::AIDAPP7>3.0.CO;2-U.

18. Liang JZ, Li RKY, Tjong SC. Effects of glass bead content and surface treatment on viscoelasticity of filled polypropylene/ elastomer hybrid composites. Polym Int. 1999;48(11):1068-72. https://doi.org/10.1002/(sici)1097-0126(199911)48:11\%3c1068:: aid-pi218\%3e3.0.co;2-k.

19. Tjong SC, Xu SA, Li RKY, Mai YW. Preparation and performance characteristics of short-glass-fiber/maleated styrene-ethylene-butylene-styrene/polypropylene hybrid composites. J Appl Polym Sci. 2002;86(5):1303-11. https://doi.org/ 10.1002/app.11095.

20. Tjong SC, Xu SA, Li RKY, Mai YW. Fracture characteristics of short glass fibre/maleated styrene-ethylene-butylene-styrene/polypropylene hybrid composite. Polym Int. 2002;51(11):1248-55. https://doi.org/10.1002/pi.867.

21. Pukánszky B, Kolárik J, Lednicky F. Mechanical Properties of Three-Component Polypropylene Composites. In: Sedlácek B, editor. Polymer Composites. Berlin: Walter de Gruyter; 1986. p. 553-60.

22. Dao KC, Hatem RA. Properties of blends of rubber talc polypropylene. Plast Eng. 1984;40(3):31.

23. Keledi G, Sudár A, Burgstaller C, Renner K, Móczó J, Pukánszky B. Tensile and impact properties of three-component PP/wood/elastomer composites. Express Polym Lett. 2012;6(3):224-36. https://doi.org/10.3144/expresspolymlett. 2012.25 .

24. Sudár A, Renner K, Móczó J, Lummerstorfer T, Burgstaller C, Jerabek M, Gahleitner M, Doshev P, Pukánszky B. Fracture resistance of hybrid PP/elastomer/wood composites. Compos Struct. 2016;141:146-54. https://doi.org/10.1016/j.compstruct.2016.01. 031.

25. Várdai R, Lummerstorfer T, Pretschuh C, Jerabek M, Gahleitner M, Faludi G, Móczó J, Pukánszky B. Impact modification of fiber reinforced polypropylene composites with flexible poly(ethylene terephthalate) fibers. Polym Int. 2021. https://doi.org/10.1002/pi. 6210.

26. Pukánszky B, Belina K, Rockenbauer A, Maurer FHJ. Effect of nucleation, filler anisotropy and orientation on the properties of PP composites. Composites. 1994;25(3):205-14. https://doi.org/ 10.1016/0010-4361(94)90018-3.

27. Varga J, Toth FS. Filled compounds of the $\beta$-modification of polypropylene. Angew Makromolek Chem. 1991;188:11-25. https:// doi.org/10.1002/apmc.1991.051880102.

28. Castillo LA, Barbosa SE, Capiati NJ (2013) Influence of talc morphology on the mechanical properties of talc filled polypropylene. J Polym Res. doi:https://doi.org/10.1007/s10965-013-0152-2.

29. Pukánszky B, Mudra I, Staniek P. Relation of crystalline structure and mechanical properties of nucleated polypropylene. J Vinyl Addit Technol. 1997;3(1):53-7. https://doi.org/10.1016/00104361(94)90018-3.

30. Horváth Z, Menyhárd A, Doshev P, Gahleitner M, Friel D, Varga J, Pukánszky B (2016) Improvement of the impact strength of ethylene-propylene random copolymers by nucleation. J Appl Polym Sci. doi:https://doi.org/10.1002/app.43823.

31. Wunderlich B. Thermal analysis of polymeric materials. Berlin: Springer; 2005.

32. Noushini A, Samali B, Vessalas K. Effect of polyvinyl alcohol (PVA) fibre on dynamic and material properties of fibre reinforced concrete. Constr Build Mater. 2013;49:374-83. https://doi.org/10. 1016/j.conbuildmat.2013.08.035.

33. Victor C, Li SW, Cynthia W. Tensile strain-hardening behavior of polyvinyl alcohol engineered cementitious composite (PVAECC). Mater J. 2001;98(6):483-92. https://doi.org/10.14359/ 10851.

34. Meng D, Huang T, Zhang YX, Lee CK. Mechanical behaviour of a polyvinyl alcohol fibre reinforced engineered cementitious composite (PVA-ECC) using local ingredients. Constr Build Mater. 2017;141:259-70. https://doi.org/10.1016/j.conbuildmat.2017.02. 158.

35. Qiu J, Lim XN, Yang EH. Fatigue-induced deterioration of the interface between micro-polyvinyl alcohol (PVA) fiber and cement matrix. Cemt Concr Res. 2016;90:127-36. https://doi.org/ 10.1016/j.cemconres.2016.08.021. 
36. Sobczak L, Jerabek M, Lummerstorfer T, Salaberger D, Renner K, Haider A. Pseudo-ductile behavior of poly(vinyl alcohol) fiberreinforced polypropylene. Polym Compos. 2019;40:4067-78. https://doi.org/10.1002/pc.25268.

37. Wu S. Estimation of the critical surface tension for polymers from molecular constitution by a modified Hildebrand-Scott equation. J Phys Chem. 1968;72(9):3332-4. https://doi.org/10.1021/j1008 $55 \mathrm{a} 044$.

38. Helmy AK, Ferreiro EA, de Bussetti SG. The surface energy of talc. J Colloid Interface Sci. 2005;285(1):314-7. https://doi.org/ 10.1016/j.jcis.2004.11.022 (PMID: 15797428).

39. Stixrude L (2002) Talc under tension and compression: Spinodal instability, elasticity, and structure. J Geophys Res. doi:https://doi. org/10.1029/2001JB001684.

40. Ndiaye D, Tidjani A. Effects of coupling agents on thermal behavior and mechanical properties of wood flour/polypropylene composites. J Compos Mater. 2012;46(24):3067-75. https://doi.org/ 10.1177/0021998311435675

41. Arjmand S, Shakeri A, Arabi H (2019) Effect of water and carbonyl sulfide toxins in gas propylene feed in polymerization process on physical properties of polypropylene. J Polym Res doi:https://doi.org/10.1007/s10965-019-1860-z.

42. Molnár J, Hertner-Horváth A, Menyhárd A (2021) Prediction of tensile modulus from calorimetric melting curves of polylactic acid with pronounced cold crystallization ability. Polym Test. doi:https://doi.org/10.1016/j.polymertesting.2021.107112.

43. Grein C, Gahleitner M. On the influence of nucleation on the toughness of iPP/EPR blends with different rubber molecular architectures. Express Polym Lett. 2008;2(6):392-7. https://doi. org/10.3144/expresspolymlett.2008.47.

44. Menyhárd A, Suba P, László Z, Fekete HM, Mester AO, Horváth Z, Vörös G, Varga J, Móczó J. Direct correlation between modulus and the crystalline structure in isotactic polypropylene. Express Polym Lett. 2015;9(3):308-20. https://doi.org/10.3144/expresspol ymlett.2015.28.

45. Molnár J, Jelinek A, Maloveczky A, Móczó J, Menyhárd A. Prediction of tensile modulus of semicrystalline polymers from a single melting curve recorded by calorimetry. J Therm Anal Calorim. 2018;134(1):401-8. https://doi.org/10.1007/s10973-018-7487-1.

46. Van der Meer DW, Pukánszky B, Vancso GJ (2002) On the dependence of impact behavior on the crystalline morphology in polypropylenes. J Macromol Sci Phys. https://doi.org/10.1081/ MB-120013087.

47. Hutley TJ, Darlington MW. Impact strength DSC correlation in mineral-filled polypropylene. Polym Comm. 1984;25(8):226-8.
48. Maiti SN, Mahapatro PK. Crystallization of i-PP/CaCO 3 composites and its correlation with tensile properties. Int J Polym Mater. 1990;14(3-4):205-22. https://doi.org/10.1080/009140390080315 14.

49. Sawatari C, Matsuo M. Elastic modulus of isotactic polypropylene in the crystal chain direction as measured by x-ray diffraction. Macromolecules. 1986;19(10):2653-6. https://doi.org/10.1021/ ma00164a036.

50. Kunugi T (1999) High-modulus and high-strength polypropylene fibers and films. In: Karger-Kocsis J, editor. Polypropylene: An A-Z reference. Dordrecht: Springer Netherlands, p. 295-300.

51. Horváth Z, Menyhárd A, Doshev $\mathrm{P}$, Gahleitner M, Tranninger C, Kheirandish S, Varga J, Pukánszky B. Effect of molecular architecture on the crystalline structure and stiffness of iPP homopolymers: Modeling based on annealing experiments. J Appl Polym Sci. 2013;130(5):3365-73. https://doi.org/10.1002/app.39585.

52. Várdai R, Ferdinánd M, Lummerstorfer T, Pretschuh C, Jerabek M, Gahleitner M, Faludi G, Móczó J, Pukánszky B. Effect of various organic fibers on the stiffness, strength and impact resistance of polypropylene; a comparison. Polym Int. 2021;70(1):145-53. https://doi.org/10.1002/pi.6105.

53. Várdai R, Lummerstorfer T, Pretschuh C, Jerabek M, Gahleitner M, Faludi G, Móczó J, Pukánszky B. Reinforcement of PP with polymer fibers: Effect of matrix characteristics, fiber type and interfacial adhesion. Polymer. 2020;190: 122203. https://doi.org/ 10.1016/j.polymer.2020.122203.

54. Gray DG. Polypropylene transcrystallization at the surface of cellulose fibers. J Polym Sci B Polym Lett Ed. 1974;12(9):509-15. https://doi.org/10.1002/pol.1974.130120903.

55. Thomason JL, Van Rooyen AA. Transcrystallized interphase in thermoplastic composites - Part II Influence of interfacial stress, cooling rate, fibre properties and polymer molecular weight. J Mater Sci. 1992;27(4):897-907. https://doi.org/10.1007/BF011 97639.

56. Thomason JL, Van Rooyen AA. Transcrystallized interphase in thermoplastic composites - Part I Influence of fibre type and crystallization temperature. J Mater Sci. 1992;27(4):889-96. https:// doi.org/10.1007/BF01197638.

Publisher's Note Springer Nature remains neutral with regard to jurisdictional claims in published maps and institutional affiliations. 